\title{
Single tyre system design and implementation using Optimization based PI Controller
}

\author{
T.Deepa, D. Subbulekshmi, S.Angalaeswari, Krithiga S.
}

\begin{abstract}
This work described in the paper to show the implementation of Proportional Integral (PI) controller, Genetic algorithm based PI (GAPI), and Particle swarm optimization based PI (PSO-PI) for a Quarter Car System. The trip comfort is developed by means of the decrease of the body acceleration caused by the car body, due to the smoothness of the road. This paper tells about the model and controllers used in the study and discuss the vehicle response results. In the conclusion, a comparison of PI, GA-PI, and PSO-PI is shown using MATLAB simulations.
\end{abstract}

Index Terms: Quarter car model, PI, GAPI, PSOPI.

\section{INTRODUCTION}

Many researches are going on for the past decades in Quarter car system. Quarter car model is the combination of mass, spring, and damper. Conventional vehicle suspension systems consist of springs and dampers. In vehicle suspensions, two objectives are there, one is to minimize the vertical forces transmitted to the passenger, and the other is to maximize the tyre-to-road contact for handling and safety.

In the traditional suspension systems we can negotiate this trade-off effectively; in active suspension systems have the possible to improve both ride quality and handling performance, with the important benefits of better braking and cornering because of condensed weight transfer. This improvement is restricted upon the feedback control of the actuators in the active suspension system.

Michiel Haemers et al [1], suggested an optimal control for a full-car electromechanical active suspension. The system is in Multi Input Multi Output in nature, so that it was represented in state space form in order to accurately simulate the behavior of a system. The active suspension control makes use of a MIMO state-feedback controller with proportional and integral actions.

The optimum value of the controller for the parameters is determined using a Genetic Algorithm, with respect to actuator constraints and without the need of further manual fine-tuning. In results, author concluded that Genetic Algorithm-PI controller was applied the full car electromechanical system which gives the satisfactory output.

Mahesh P. Nagarkar et al, tells about mathematical modelling and control, and multi-objective optimization of an active nonlinear quarter car suspension system [2,9]. A nonlinear Two degrees of freedom nonlinear single tyre car model having quadratic nonlinearities in the tyre and cubic

Revised Manuscript Received on July 22, 2019.

T.Deepa,School of Electrical Engineering, VIT, Chennai, India.

D.Subbulekshmi, School of Electrical Engineering, VIT, Chennai, India

S.Angalaeswari, School of Electrical Engineering, VIT, Chennai, India.

Krithiga S. School of Electrical Engineering, VIT, Chennai, India.

nonlinearity in spring is developed and implemented for control applications.

Muhammad Ibrahim Faruk [3] designed two control techniques. They are a conventional PID and intelligent Fuzzy Logic Control (FLC). Then the results are compared for the passive quarter car suspension system. MATLAB Simulink was used for both designs, investigation of the effects of the two control techniques, and their comparison and verification of the results obtained and the results are shows the effectiveness of the controllers.

After the comparison of both the controller, results shows that both control logics implemented performed very well to some extent. A future work is to apply the control scheme to half and full model car system, and also test the performance using real practical system.

M Senthil Kumar \& S Vijayarangan [4] considered, three degrees-of-freedom is considered. So that simplified analysis were made and also represents most of the features of the full model. The model consists of (i) passenger seat and (ii) sprung mass and (iii) unsprung mass, which refers to the wheel assembly mass. here author neglected the tyre damping. The passenger seat, and suspension, tyre are modelled by springs.

Mahesh P. Nagarkar et a [7], represented the mathematical modelling of a nonlinear quarter car (NLQC). The nonlinear single tyre model consists of both quadratic tyre and cubic stiff nesses in suspension spring. Conventional PID and intelligent FLC are implemented as a controller to minimize frequency weighted RMS sprung mass acceleration, VDV, RMS suspension space requirement, and RMS tyre deflection along with RMS optimal control force.

The PID and FLC strategies are used for implementation of a nonlinear quarter car system. Controller parameters such as $\mathrm{K}_{\mathrm{p}}, \mathrm{K}_{\mathrm{i}}$, and $\mathrm{K}_{\mathrm{d}}$ constants of the PID controller and range of input-output membership functions and scaling factors of the FLC are tuned according to NSGA-II algorithm.

In order to improve the ride comfort of the system, GA based FLC active controller reduces the frequency-weighted RMS acceleration and VDV in comparison to that of the PID and passive suspension system, which has been proven by the numerical simulation in the literature. Frequency domain analysis results shows that the active control system experiences reduced overshoot when compared to that of passive system.

Min Yu et al [5], taken Series Active Variable Geometry suspension for quarter car model. Author designed the $\mathrm{H}$-infinity control and the output performance of the system was also verified [10]- [11].

MP Nagarkar [6] taken nonlinear quarter car model and also developed MATLAB simulation. author also deisgned Proportional

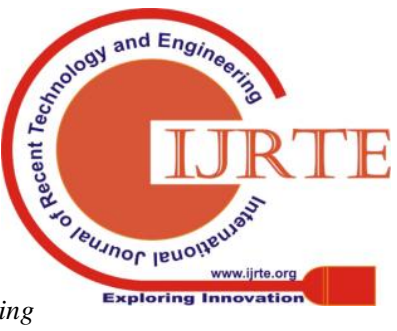


integral and Derivative Controller and Linear Quadretic Regulator controller and verified the output. Finally he proved PID is giving better ride and comfort.

Mahesh P.Nagarkar et al [7], concentrated on vibration to give optimized comfort so the simulation results shows the improvement of comfort and helath criteria. He also implemented non dominating sort genetic algorithm and multi objective particle swarm optimization [12].

Nitish Katal, Sanjay Kr. Singh [8], designed a quarter car suspension model and improved the system response by employing a GA based PID controller which in turn improve the ride comfort and stability by decreasing the body acceleration in vehicles produced by the road indiscretions.

In the conclusion, good response with less oscillation is obtained using GA based optimization method related to the traditional PID tuning method. He proved that the Genetic Algorithm realized the improved steady-state response and performance indices. T. Deepa and D. Subbulekshmi [13] explained about the design of 2 term and 3 term conventional controller in magnetic levitation system..

\section{PHYSICAL MODEL}

The quarter car model consisting of mass, spring and damper system is as shown in Figure 1[14].

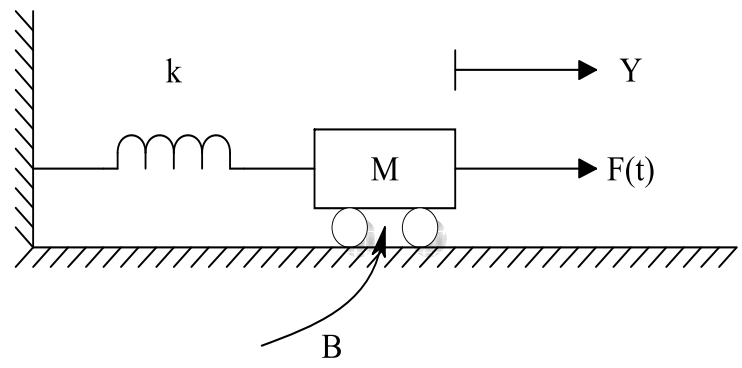

$\mathrm{F}$

igure 1 Mechanical System

The parameters of the mechanical systems are

$\mathrm{M}=100 \mathrm{Kg}, \mathrm{B}=100 \mathrm{~N} / \mathrm{m} / \mathrm{Sec}, \mathrm{k}=10000 \mathrm{~N} / \mathrm{m}$

The mathematical equation of the quarter car model is derived as given in equation 1 .

$$
\frac{Y(s)}{F(s)}=\frac{1}{M s^{2}+B s+k}
$$

After substituting the parameters of the mechanical systems, the transfer function is given in equation 2 .

$$
\frac{Y(s)}{F(s)}=\frac{0.01}{s^{2}+10 s+100}
$$

\section{CONTROLLER DESIGN}

The PI controller structure is

$$
c(s)=K_{p}+\frac{K_{i}}{s}
$$

The PI controller parameters are getting from Ziegler Nicholas method. The values of $K_{p}$ and $K_{i}$ are tabulated. PI controller parameters tuned using Genetic Algorithm and particle swarm optimization techniques.
During training cycle the GA constraints are

Population Size $\quad=10$

Cross over rate $\quad=0.8$

Mutation Rate $\quad=0.01$

Number of generation $\quad=100$

Population type = double

Selection $=$ Roulette wheel

Following PSO parameters are selected for the training cycle of the Quarter car model

No of birds $\mathrm{n}_{\mathrm{b}} \quad=10$

Maximum number of "birds steps" $\quad=50$

Velocity constant $\mathrm{c}_{1} \quad=0.4$

Velocity constant $\mathrm{c}_{2} \quad=0.4$

PSO momentum or inertia $\mathrm{w} \quad=0.9$

Table 1 provides the values of PI controller constants.

Table 1 PI controller constants

\begin{tabular}{|l|l|l|l|}
\hline PI constants & ZN-PI & GAPI & PSOPI \\
\hline$K_{p}$ & 4158 & 2021 & 1.4026 \\
\hline$K_{i}$ & $4.916 \mathrm{e}^{4}$ & $1.3165 \mathrm{e}^{4}$ & $2.4357 \mathrm{e}^{4}$ \\
\hline
\end{tabular}

\section{RESULTS AND DISCUSSION}

The PSOPI control method has been realized in Matlab/Simulink software and the results are offered. Integral Square Error (ISE), Integral Absolute Error (IAE) are calculated using the above three analysis. PI, GAPI and PSOPI control scheme performances are compared.

The set point changes and disturbance rejection is also satisfactory for illustrating the performance of the three various control strategies.

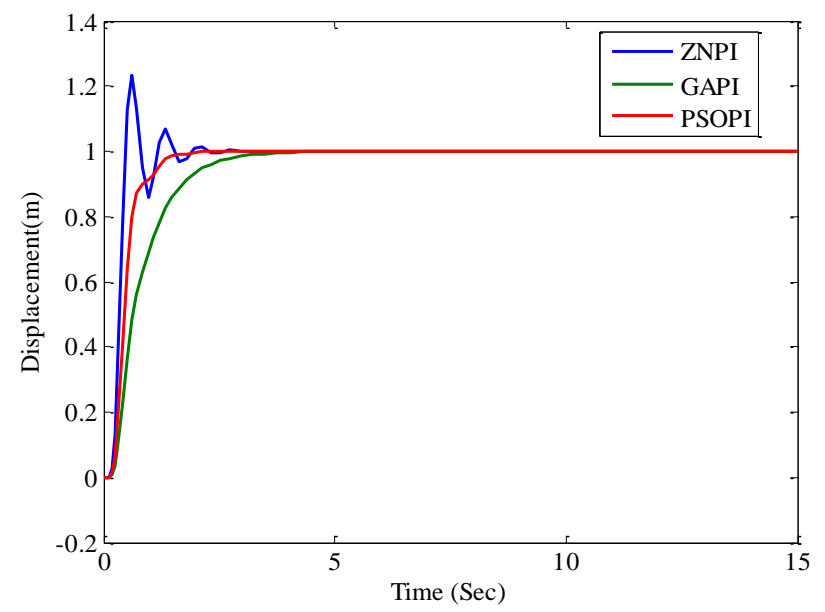

Figure 2 Closed loop response 


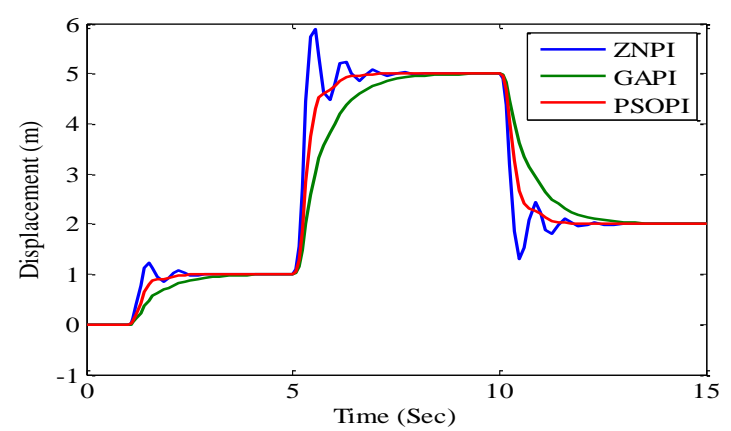

Figure 3Step changing response

Figure 2, Figure 3 and Figure 4 are the closed loop, step changing and regulatory responses of ZNPI, GAPI and PSOPI respectively. The step changing response is drawn for $1 \mathrm{~m}$ displacement up to $5 \mathrm{sec}$, after that it increases from 1 to $5 \mathrm{~m}$. again it decrease from 5 to $2 \mathrm{~m}$ at $10 \mathrm{sec}$.

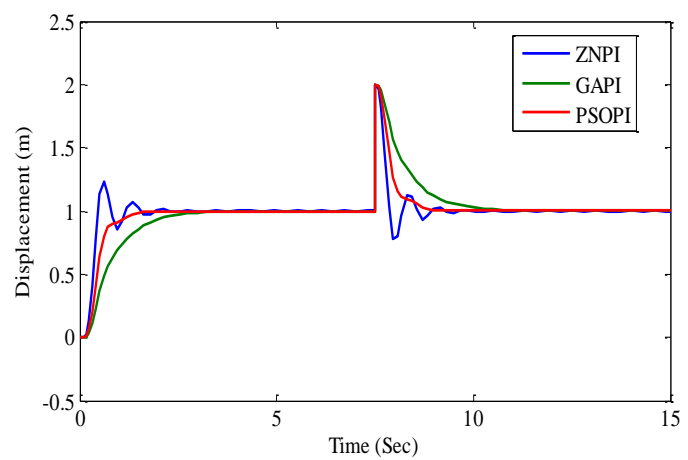

Figure 4 a Regulatory Response

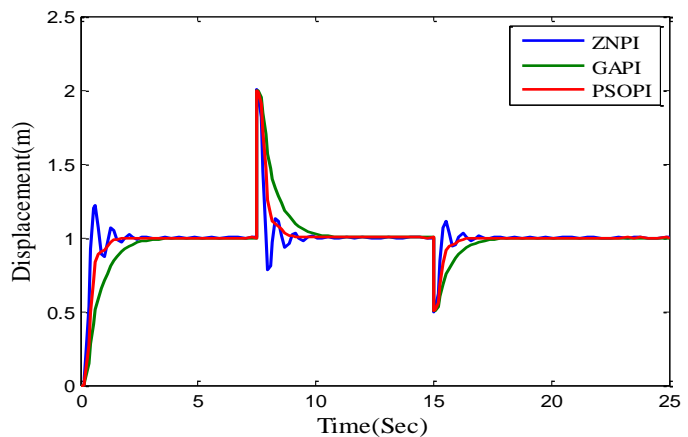

Figure 4 b Regulatory responses

The ISE and IAE values are calculated and the performances are tabulated in Table 2 using the proposed controller.

Table 2 Performance Specifications

\begin{tabular}{|l|l|l|l|}
\hline $\begin{array}{l}\text { Performance } \\
\text { Criteria }\end{array}$ & ZN PI & GAPI & PSOPI \\
\hline ISE & $\mathbf{0 . 4 6 9 7 1 9}$ & $\mathbf{0 . 5 7 3 3 3}$ & $\mathbf{0 . 4 1 6 1 3 7}$ \\
\hline IAE & $\mathbf{0 . 5 5 7 6 0 4}$ & $\mathbf{0 . 7 4 3 1 1 4}$ & $\mathbf{0 . 5 0 9 9 7 4}$ \\
\hline
\end{tabular}

\section{CONClusion}

The transfer function of the quarter car model is derived from the mathematical model. The PI controller is designed from the second order system using $\mathrm{ZN}$ method. The PI controller parameters are tuned using GA and PSO optimization techniques. The analysis is made using Simulink and the performances are tabulated. From these analyses, it is to be found the performance criteria for PSOPI is less while related to ZNPI and GAPI..

\section{REFERENCES}

1. Michiel Haemers, Stijn Derammelaere, Clara-Mihaela Ionescu, Kurt Stockman, Jasper De Viaene, Florian Verbelen, "Proportional-Integral State-Feedback Controller Optimization for a Full-Car Active Suspension Setup using a Genetic Algorithm", IFAC Conference on Advances in Proportional Integral-Derivative Control, vol 51 [4], pp.1-6, 2018.

[2] Mahesh P. Nagarkar, Yogesh J. Bhalerao, Gahininath J. Vikhe Patil and Rahul N. Zaware Patil, "GA-based multi-objective optimization of active nonlinear quarter car suspension system-PID and fuzzy logic control", International Journal of Mechanical and Materials Engineering, vol 13 [10], pp. 1-20, 2018.

[3] Muhammad Ibrahim Faruk, Amir Bature, Suleeiman Babani, Najib Dankadai, "CONVENTIONAL AND INTELLIGENT CONTROLLER FOR QUARTER CAR SUSPENSION SYSTEM”, international Journal of Technical Research and Applications vol.2 [1], PP. 24-27, 2014

[4] M Senthil Kumar \& S Vijayarangan, Design of LQR controller for active suspension system", Indian Journal of Engineering \& Materials Sciences Vol. 13, pp. 173-179, 2006.

[5] Min Yu, Simos A.Evangelou, Daniele Dini, “ Model Identification and Control for a Car test rig of series active variable geometry suspension", IFAC papers on line, vol.50[1], pp.3376-3381, 2017.

[6] MP Nagarkar, YJ Bhalerao, GJ Vikhe Patil, RN Zaware Patil, "Multi objective optimization of nonlinear quarter car suspension system PID and LQR control”, Procedia Manufacturing, vol 20, pp. 420-427, 2018.

[7] Mahesh P.Nagarkar, Gahininath J.Vikhe Patil, Rahul N.Zaware Patil, "Optimization of nonlinear quarter car suspension- seat- driver model", Journal of advanced research, vol.7 [6], pp.991-1007,2006.

[8] Nitish Katal, Sanjay Kr. Singh, "Optimization of PID Controller for Quarter-Car Suspension System using Genetic Algorithm", International Journal of Advanced Research in Computer Engineering \& Technology (IJARCET) vol. 1[7], pp 30-32, 2012.

[9] Ganesh D. Shelke, Anirban C. Mitra, Vinay R.Varude, "Validation of simulation and analytical model of nonlinear passive vehicle suspension system for quarter car", Materials today, vol.5, pp. 19294-19302, 2018.

[10] Min Yu, Carlos Arana, Simos A. Evangelou, Daniele Dini, George D. Cleaver, "Parallel Active Link Suspension: A Quarter-Car Experimental Study", IEEE/ASME TRANSACTIONS ON MECHATRONICS, vol. 23[5], pp.2066-2077,2018.

[11] Hao Zhang, Qianqian Hong, Huaicheng Yan, Fuwen Yang, Ge Guo, "Event-Based Distributed $\mathrm{H} \infty$ Filtering Networks of 2-DOF Quarter-Car Suspension Systems", IEEE TRANSACTIONS ON INDUSTRIAL INFORMATICS, vol.13 [1], pp.312-321,2017.

[12] Haiping Du, Weihua Li, and Nong Zhang, "Integrated Seat and Suspension Control for a Quarter Car With Driver Model", IEEE TRANSACTIONS ON VEHICULAR TECHNOLOGY, vol.61[9], pp.3893- 3908, 2012.

[13] T. Deepa and D. Subbulekshmi, "Design and Implementation of 2 Term and 3 Term Controllers for Magnetic Levitation System”, International Journal of Mechanical Engineering and Technology (IJMET), vol 9[6], pp. 343-350,2018.

[14] T.Deepa, S.Angalaeswari and V. Balaji,Turning of PI controller parameters using genetic algorithm (GA) for quarter car applications,International journal of Pure and Applied Mathematics, vol.120(6), pp.no.2007-2015,2018.

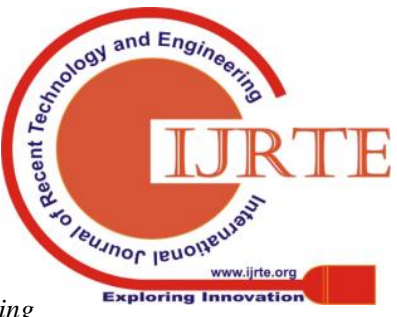
\& Sciences Publication 